\title{
Meeting the productivity challenge below 2.5 kilometres
}

\author{
D Morrison Centre for Excellence in Mining Innovation, Canada
}

\begin{abstract}
The major trends in the global mining industry are well established and will continue; more metal resources are being produced from underground mines than from surface mines, grades are declining in many mines, production costs are increasing as mines become deeper and hotter, and the rate of discovery of new mines remains low. Furthermore, even those mines that are discovered will be ever more remote from the infrastructure that connects them to the market - adding the extra cost of transportation from infrastructure to market, to the cost of production. This increases the requirement for higher profitability.

In addition to these internal industry issues, the external pressure will continue to increase and intensify; the public's demand for greater protection of the environment, especially northern sensitive ecologies, will intensify along with the desire to see populations living close to mines to enjoy greater share of the benefits from mines. The external pressures are relatively new but the internal trends have been with us for several years and industry has been slow to respond. However, the slow recovery means all these factors must be addressed; but for all these demands to be met and for declining performances to be reversed, major changes in the way mines operate have to occur.
\end{abstract}

Simply waiting for an increase in commodity prices is not a viable option - there are few indications that rapid increases will happen, and in any event, costs are likely to escalate at least at the same rate. The demographics of the industry are going to change very rapidly - much faster than the typical $25 \%$ replacement rate. The real problem is that experience will be lost at a rate far greater than individuals, because experienced retirees are replaced by relative novices. This will inevitably lead to poorer planning, more errors and subsequent cost increases that will accelerate with time. Continuing to use the 'experience-intensive' processes we use today is a recipe for very poor financial performance, both in new project implementation and in routine operations. We believe that new communications, digital and analytical technologies, supplied by sensor data and managed by artificial intelligence will not decrease employment in mines; we believe these technologies will be essential for mines to cope with the rapid decrease in the number of experienced employees.

It is 35 years since the last major transformation in productive technology. The next change is long overdue, and although improved data management and digital mining will help, it is simply not sufficient. Yes, we can use software to improve several aspects of daily operations. We can use drones to assess the stability conditions in open stopes and orepasses. There are probabilistic models for optimising the best and most robust of thousands of production planning options - SOT Plus is one example. But in the end, the business of mining is breaking and moving many thousands of tonnes of rock every day, and unless there are major changes in the way we do this, many operations may not be able to survive the future commodity price projections.

Since more than 95\% of the material mines produce is waste, we need to demonstrate and assure the public that we can be relied upon to provide a far higher level of environmental stewardship than before, and our approach to water usage and water management has to change dramatically. This is the only way to reduce the time to mine permit and social license to operate. And, finally, we have to develop technology that will decrease the cost and risk of finding new mines and enabling industrial-scale developments in very remote locations. Without these changes, many mines around the world will not be fit for purpose in the next decade. 
When problems seem to be intractable to more and more focus, it is often valuable to change the perspective - look further afield - in space and time. Some of our best ideas come from looking at how things are done in different places, in different industries and, most importantly, in earlier times. The solutions developed to circumvent the limitations of pre-industrial society and early industrialisation have lessons to teach us.

In many cases, the ideas that are currently being considered as the primary target for innovation tend to focus on costs - reducing the direct cost of labour through automation, or reducing the cost of ventilation by eliminating diesel particulates. The other important factor, which is too often over-looked, is time; the time to find the next orebody, the time to first production, the time to obtain a mining permit, the time necessary to obtain social licence to operate. All these delays have been increasing and it is sometimes worth spending a little more money to gain a lot of time. Just as we need to work on ideas that reduce the cost of doing things, we must also work on ideas that reduce the time it takes to get things done, and get them done better.

Keywords: productivity, cooling, innovation, time-effectiveness, energy-effectiveness

\section{A targeted approach}

The Centre for Excellence in Mining Innovation (CEMI) was created in 2007 by Inco (now Vale) and Xstrata (now Glencore) to develop innovations to support deep underground base metal mining. In 2010, Rio Tinto joined in to have contract research projects for their high-stress block caving operations. We believe it important to make the distinction between research and innovation - terms that are often used interchangeably. In its simplest form, the distinction is that research produces a technical result and innovation produces a commercial result. CEMI's focus is innovation; turning the knowledge created by research, today's or yesterday's, into practical and commercially viable solutions. If mines cannot buy or lease technology or hire people with new techniques, they cannot adopt innovation. An innovation has to improve performance in many mines - a one-off demonstration is not good enough. Innovation is only successful when it changes routine operational practice across a whole segment of the industry, not simply solving the problem of one mine.

CEMI's projects have to improve at least one of three factors; up-front capital cost, the time to first production (revenue) and the return on investment (ROI). Taken together, these factors impact the net present value (NPV) of any project, and if we cannot see how a project will impact this number positively, it is not a project for us. But achieving significant improvement in NPV does demand re-examining the fundamentals of what mines do and why.

Finding a source of innovation can be difficult; one option is to invest a great deal of research and hope that some of the ideas have applications to the priority problems in the industry; another is to throw open lots of ideas from many other industries and places - 'open innovation'. Over the last few years, CEMI has developed the targeted approach; we target a particular problem, target the people in the mining business who have been confronted with this - in other places and in other times - and have come up with partial solutions or discovered the fundamental roadblock, target the researchers that might be able to overcome the remaining part of the problem and target the commercial partners we think can turn this solution into a commercially viable product or service.

Since we are based in Sudbury, Northern Ontario, CEMI's primary focus over the last five years has been underground mine productivity below $2.5 \mathrm{~km}$ depth. This is the target depth of the Ultra-Deep Mining Network (UDMN) funded by the federal government of Canada, and now assisted by the Ontario government, but always matched by industry funding. The $2.5 \mathrm{~km}$ depth is just the critical depth for many mines in central Canada, but the physical criteria that define the problem are actually the rock stresses and the heat at these depths. These same conditions afflict deep metal mines around the world, regardless of depth. The UDMN is addressing global problems. 


\section{Practical examples}

\subsection{Advance rates}

Advance rates have been declining for many decades and the reasons are well understood. First, the demand to reduce injuries and fatalities has meant better operational protocols and much more ground control. Second, as mines became deeper and rock stresses higher, the need for even greater ground control increased further and as mines began to use economies of scale, underground equipment and underground excavations became larger also. Larger, wider drifts need more reinforcement to maintain stability than smaller ones, so the time taken to install ground support had to increase yet again.

Drift advance is one of several activities in the mining cycle, but one of the most critical. Decreasing the rate of advance has the effect of increasing the time to first production and decreases the NPV of a new project. There are many things that can be done to improve the performance of an active mine, but if the NPV of any project is too small, the capital investment needed to start production will not be approved, and all future opportunities for improvement are lost. Slowing the time to first production - by decreasing advance rates in underground mines or by increasing strip ratios in open pit mines - kills projects.

The conventional sequence in drift development is to remove broken rock from the previous blast, install ground support, drill the face and charge the face, and currently a common cycle-time for mines with a face area of $20-30 \mathrm{~m}^{2}\left(5 \mathrm{~m}^{2} \pm 0.5 \mathrm{~m}\right)$ is around 16 hours. This is close to the worst possible cycle-time because it is very difficult to make productive use of the remaining eight hours out of 24 , and the individual activities cannot be contracted sufficiently to achieve a total 10.5 hour cycle-time which would enable two full cycles per 24 hour period. In mining operations where the ground conditions include strainbursting from the face, prudent ground control systems now limit the advance rate to less than $3 \mathrm{~m} / \mathrm{day}$, and while mining contractors can offer higher rates, none offer more than $5 \mathrm{~m} /$ day.

In order to increase the advance rate, the best option is to change the current paradigm by creating a work process with concurrent activities. This involved developing a canopy system that provides a physical barrier to all the rock-related hazards before permanent ground support is installed, and allows face drilling and explosive charging to be accomplished using the face equipment (jumbo), while permanent ground support was being installed behind the face equipment. This allows the face activities to be completed in around eight hours and leaves two hours for the removal of broken rock, and the installation of the canopy system has to be completed in around two hours. Using a continuous loading machine to empty the face of broken rock leaves sufficient time to install the canopy system. Event simulations show that achieving these targets enables an advance rate of 8-10 $\mathrm{m} /$ day - more than double the current routine advance rate. And in achieving the reduced face cycle and reduce mucking cycle, the kinds of time-saving opportunities used in the past were critically important.

Finally, because of the current limitations of drill-blast systems, there is renewed interest in mechanised rock excavation and they have a great deal to offer in soft rock conditions where the high rate of daily advance is sufficient to compensate for the cost of the set-up time. There are still difficulties with rock curing in the hardest rock and while these may be overcome in time, the risk of delays caused by strainbursting under high-stress conditions will remain problematical. However, comparing the performance of mechanical excavation to current drill-blast regimes does not take into account the lack of leaning of the process in drill-blast systems. More than anything, mechanical excavation equipment is 'a system' designed for time efficiency; only once this has been done for drill-blast systems will the merits of the two processes become clear. 


\section{$3 \quad$ Heat management}

\subsection{Introduce active cooling}

The primary role of mine ventilation is to remove heat from the mine; delivering breathable air for people is easily achieved and is a secondary, if not tertiary objective after ensuring the equipment can operate effectively. Until recently, the most common approach has been to increase the rate of flow of ventilation to remove heat, but this is becoming prohibitively expensive for very deep mines. The most direct route to reducing heat and humidity is to introduce cooling - either cooling the environment or cooling the critical components in the system, most often the people, but increasingly also the electronics. The conventional approach to mine cooling is mechanical chilling of the air but this increases the consumption of electricity often the highest non-labour cost in the operation.

In the deep mines in Central Canada - Ontario, Quebec and Manitoba - heat management has become at least as great a technical challenge as high rock stresses. In Sudbury, the critical depth is $2.5 \mathrm{~km}$, but in Timmins, where the heat gradient is slightly lower, Kidd Creek Mine can operate at $2.74 \mathrm{~km}(9,000 \mathrm{ft})$ without using work-rest regimes. East of Sudbury, the gold mines in Val d'Or, Quebec have a slightly higher geothermal gradient so that the host rock at a given depth is hotter there than they are in Sudbury. Some of these gold mines have already implemented mechanical air chilling to reduce the need to implement work-rest regimes for operators. But for much larger-volume base metal mining operations anywhere in the world, this approach is unlikely ever to be cost effective.

One source of cooling is the expansion of compressed air, but mine regulations do not permit the use of compressor air because of the entrained oil in the air stream. However, Ontario had an early example of producing fresh compressed air - the Ragged Chutes Hydraulic Air Compressor. This produced compressed air for all of the mines surrounding Cobalt, Ontario from 1910 onwards. It used the height differential of a small waterfall on the Montreal River to produce fresh compressed air. Upstream of the waterfall water was

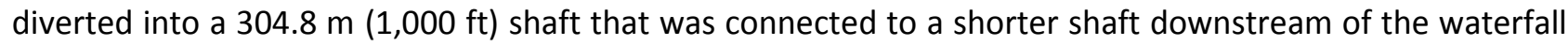
by a short tunnel. The height of the drop controls the degree of compression; this height was chosen to deliver roughly 9 bar (130 psi), which met the needs of the pneumatic equipment of the time. A series of pipes at the head of the shaft facilitated the entrainment of air bubbles in the water column in the shaft upstream of the waterfall. Theses bubbles separate out at the roof of the tunnel and the compressed air is captured in an off-take cavern. The water in the lower part of the tunnel was pushed up the shorter downstream shaft and delivered back into the river. The captured fresh compressed air was sufficient to supply the needs of all of the silver mines in the region for their pneumatic equipment and during the highwater flow periods in the spring, excess compressed air had to be blown off into the atmosphere.

Dr Dean Millar, Director of Energy, Renewable and Carbon Management at MIRARCO, based at Laurentian University, has rejuvenated this technique for the modern era. His innovations disconnect it from the need for a river source and have combined the compressed air production processes into a single shaft. The first hydraulic air compressor to be built in Canada in over 100 years was completed in June 2017, at the Dynamic Earth facility in Sudbury. This was funded through CEMI's UDMN program and is a one-third scale demonstration version of the Ragged Chutes facility that, in addition to its research applications, will also be used to make the business case for a full-scale version to be constructed in an active mining operation to deliver cooling to deep underground operations.

\subsection{Reducing ventilation on demand}

The dominant regulation for delivering ventilation is 100 CFM per brake horsepower underground; the more horsepower underground, the more ventilation is required. In Ontario, with relatively high electricity rates, the largest non-labour cost for many mines is the energy for ventilation. For over 35 years, increasing production in the open-stoping mines that produce $3,000-8,000$ tpd has been achieved by increasing the size of the equipment, especially the load-haul-dump units (LHDs) and trucks, which in turn means increasing 
ventilation demand. Planning to use haulage trucks that essentially fill the main access drive requires a second ventilation drive that almost doubles the upfront capital cost.

In large block caving mines producing more than 100,000 tpd, increasing production has meant increasing the number of haulage units rather than the size of individual units. Because there are so many active drawdrives, each with multiple active drawpoints, the approach has been to use many more, smaller LHDs because they use smaller drives and this reduces the time and cost of access development. However, in addition to increasing the demand for ventilation flow that ensures acceptable air quality conditions, it increases equipment congestion that also constrains the system's ability to achieve production targets.

\section{$4 \quad$ Electrification of underground equipment}

Recently, there has been a great deal of interest in the underground mining innovation space towards a shift from diesel-driven haulage units - LHDs - to battery-powered electric drives in order to address the heat management issue at depth.

Electric drives have a great deal to offer - the high early torque characteristics of electric drives are far better suited to the demand cycle of the typical production LHD than are diesel engines - and they always have been. But for the last 30 years, the demand for electric LHDs - and any effort by original equipment manufacturers (OEMs) to promote them as a superior product - has been virtually non-existent.

In the late 1980s, Inco's Crean Hill mine implemented a fleet of electric LHDs powered by tethered umbilical cables. It was new technology and had lots of problems - wear on the umbilical cables at drift intersections, the tangling of the umbilical spools with ventilation tubing, and poorly placed cable connection points. None of these problems were insurmountable, but the lack of a formal change management process and the effective resistance of the workforce to an unfamiliar and less flexible system was enough to kill the idea. And kill it for nearly thirty years - until today when battery technology might make an untethered electric LHD possible. For much of their working lives, production LHDs travel along a limited number of relatively short routes - easily serviced by power cables. All the operational problems of direct-power electric LHDs could have been addressed over 30 years ago, and the higher ventilation and maintenance costs imposed on industry by 'more flexible' untethered diesel-powered vehicles could have been avoided.

The current level of interest in battery-driven electric vehicles is now very high, and one Canadian mining company has even set itself the challenge of becoming 'Canada's first all-electric mine' - some 30 years after Crean Hill. Today, this means a fleet of production vehicles powered exclusively by battery-powered electric motors. The aspiration may be difficult to satisfy since present battery technology can only power small production LHD units for about two hours, and the immediate target is only four continuous hours of continuous activity. While battery technology will undoubtedly improve, this is still a long way from a full production shift.

However, there are other problems with the current approach. Firstly, many mine regulations stipulate ventilation requirements relative to brake horsepower, e.g. 100 CFM per brake horsepower, but make no distinction between diesel or electric. So, although the requirement to dilute diesel emissions will be reduced, the overall requirements for ventilation will remain. Secondly, and more importantly, there is a fundamental problem with the LHD. Generally, the typical diesel LHD weighs about three times the load it carries and it returns empty. This means that for every tonne of material moved a certain distance, six tonnes of LHD had to be moved; roughly $80 \%$ of the diesel burned - or energy consumed - is used to move the LHD and $20 \%$ is used to move product. Assuming diesel and electric engines are roughly the same weight but batteries weigh more than diesel, the ratio of the weight of the equipment to the weight of the product is getting worse. Using more batteries to prolong the active capability of LHDs will mean even more of the energy expenditure on moving equipment and even less on moving ore. The assessment of LHDs is typically based on its utilisation of efficiency, not its effectiveness. The LHD is less than $10 \%$ effective, spending less than $10 \%$ of the cycle time on the essential task of digging and dumping product and leaving the ore untouched while traveling. 
Electrically powered LHDs have a great deal to offer in terms of effectiveness and reducing ventilation demand, and batteries have a role to play in relatively specialised, short-duration tasks. However, it is important to focus on the potential of electric-driven equipment for reducing mine production costs and not delay its re-introduction because of the limitations of battery technology.

\section{Conclusion}

Ultimately, the primary measure of success for mines is productivity; the total cost of production and maintenance labour, the power consumption and the rate, and the cost and quality of the ore that is produced. The speed and efficiency of breaking rock (ore) and moving is the primary physical challenge mines have to address. While this can sound mundane to many people, mines actually have to confront the fundamental forces of the universe; gravity, time, heat and friction - and have to come up with practical solutions.

Increasing advance rates is not an equipment problem. Reducing the development cycle-time is a time-optimisation problem - the leaning of a sequence of activities, making them as time-efficient as possible. Yes, it involves the novel use of equipment but these are simply the outcomes of the time-optimisation process. To enable two full cycles per day, the entire cycle-time must be reduced to less than 10.5 hours, and this involves completing face activities concurrently and moving over 300 tonnes of rock per hour. Once this can be achieved, the same system can be applied to production from a single drawpoint.

In high temperature and humidity conditions, cooling systems of some kind must be introduced. Introducing high-cost chilling systems are prohibitively expensive for large-scale, base metal even if they can be temporarily effective for some precious metal mines. Introducing low-cost, fresh, compressed air is the first step on the way to delivering low-cost cooling underground, and replicating the Ragged Chutes facility would provide nine-fold expansion of fresh air. However, progress toward the application of liquid air systems with over 60-fold expansion capacity is already being made.

The re-introduction of electric motors to mobilise the equipment used to transport ore and rock in deep underground operations is long overdue and is now essential and urgent. Combined with automation and artificial intelligence, these systems will be an important part of the future of deep underground mines.

For almost 35 years, mines have relied on increasing economies of scale and tactical solutions that change very little, but these have now run their course. It is no longer sufficient simply to consider minor improvements to the efficiency of the current system. What is required is a whole new approach a re-examination of all the processes we use at a fundamental level. The ultimate goal is a successful, productive and profitable mining industry, contributing to a globally sustainable society.

The challenges of highly productive mining systems well below $2.5 \mathrm{~km}$ will require the re-examination of the fundamental processes we use, considering energy and time. There are many technological solutions open to us, many of which have been tried in other places and other times, and whose lack of success in our industry was because they were before their time and needed new technologies that are now available to us. At CEMI, we believe each of the new approaches we have addressed here, and many others besides, have their rightful place in the way mining will operate in the future. Bringing them into common practice means that the coming transition in deep underground mining will be one of the most exciting and successful transitions the industry has ever experienced. 